\title{
Enhanced Aryltetralin Lignans Production in Linum Adventi-Tious Root Cultures
}

\author{
Michela Alfieri ${ }^{1}$, Iride Mascheretti ${ }^{2}$, Roméo A. Dougué Kentsop ${ }^{2}{ }^{\mathbb{D}}$, Roberto Consonni ${ }^{1}$, Franca Locatelli ${ }^{2}$, \\ Monica Mattana ${ }^{2}$ and Gianluca Ottolina ${ }^{1, *}$
}

1 Institute of Chemical Sciences and Technologies "Giulio Natta", National Research Council, Via Mario Bianco 9, 20131 Milan, Italy; michela.alfieri@scitec.cnr.it (M.A.); roberto.consonni@scitec.cnr.it (R.C.)

2 Institute of Agricultural Biology and Biotechnology, National Research Council, Via Bassini 15, 20133 Milan, Italy; iride.mascheretti@ibba.cnr.it (I.M.); romeo.dougue@ibba.cnr.it (R.A.D.K.); franca.locatelli@ibba.cnr.it (F.L.); monica.mattana@ibba.cnr.it (M.M.)

* Correspondence: gianluca.ottolina@scitec.cnr.it; Tel.: +39-0228500021; Fax: +39-0228901239

\section{check for} updates

Citation: Alfieri, M.; Mascheretti, I.; Dougué Kentsop, R.A.; Consonni, R.; Locatelli, F.; Mattana, M.; Ottolina, G. Enhanced Aryltetralin Lignans Production in Linum Adventi-Tious Root Cultures. Molecules 2021, 26, 5189. https://doi.org/10.3390/ molecules26175189

Academic Editors: Toyonobu Usuki, Akira Kawamura and Masaru Hashimoto

Received: 29 July 2021

Accepted: 23 August 2021

Published: 27 August 2021

Publisher's Note: MDPI stays neutral with regard to jurisdictional claims in published maps and institutional affiliations.

Copyright: (c) 2021 by the authors. Licensee MDPI, Basel, Switzerland. This article is an open access article distributed under the terms and conditions of the Creative Commons Attribution (CC BY) license (https:/ / creativecommons.org/licenses/by/ $4.0 /)$.

\begin{abstract}
Lignans are the main secondary metabolites synthetized by Linum species as plant defense molecules. They are also valuable for human health, in particular, for their potent antiviral and antineoplastic properties. In this study, the adventitious root cultures of three Linum species $(L$. flavum, L. mucronatum and L. dolomiticum) were developed to produce aryltetralin lignans. The effect of two elicitors, methyl jasmonate and coronatine, on aryltetralin lignans production was also evaluated. The adventitious root cultures from L. dolomiticum were obtained and analyzed for the first time and resulted as the best producer for all the aryltetralins highlighted in this system: Podophyllotoxin, 6-methoxypodophyllotoxin and 6-methoxypodophyllotoxin-7-O- $\beta$-glucoside, the last showing a productivity of $92.6 \mathrm{mg} / \mathrm{g}$ DW. The two elicitors differently affected the production of the 6-methoxypodophyllotoxin and 6-methoxypodophyllotoxin-7-O- $\beta$-glucoside.
\end{abstract}

Keywords: Linum; aryltetralin lignans; 6-methoxypodophyllotoxin; elicitor; NMR; methyl jasmonate; coronatine

\section{Introduction}

Lignans are secondary metabolites widely distributed in higher plants that demonstrate a wide range of biological activities. The main function of these metabolites is to protect plants against herbivores and pathogens and to help their adaptation to adverse environmental conditions. Moreover, most of these compounds also show biological activities including antiviral, cytotoxic, antioxidant, hepatoprotective, anti-inflammatory and antiangiogenic [1-4]. In particular, the lignans showing cytotoxic activity, such as podophyllotoxin (PTOX) and 6-methoxy-podophyllotoxin (MPTOX), can be used as lead compounds for the development of new therapeutic drug for their anticancer properties [5].

The biosynthesis of lignans starts from a regio- and stereoselective, oxidative coupling of two coniferyl alcohol or their biogenetic equivalents (propenyl phenols), to form a large variety of distinct molecules [6,7]. On the base of their chemical structure, they are divided into several classes. The aryltetralin-type lignans (ATLs) have gained attention since the most representative compound, podophyllotoxin, is one of the main precursors of the effective anticancer drugs etoposide, teniposide, GL331, NK611 and TOP-53, which exhibit inhibitory action against the enzyme topoisomerase II [8]. These semisynthetic derivatives are being successfully used to treat several cancers such as lung, testicular, ovarian, stomach and non-Hodgkin lymphoma [9].

Despite the recent advances in the chemical synthesis of the aryltetralin lactone skeleton [10-12], the semisynthesis strategy is still preferred to achieve the target drugs. In nature, PTOX is found in the roots and rhizomes of either the Podophyllum peltatum and 
Podophyllum hexandrum, but due to overcollection, these species are listed as endangered. In addition to these two recognized producers, there are many other plants being studied for PTOX, or aryltetralin lactone lignans in general, belonging to different clades/families, such as Laminaceae, Apiaceae, conifer species belonging to Podocarpus, Callitris or Juniperus [13]. Up to now, a very important source of lignans is represented by the genus Linum, family Linaceae, which includes about 230 species, divided into six sections based on their morphology: Linum, Dasylinum, Linastrum, Cathartolinum, Syllinum and Cliococca [14]. The ATLs are found mainly in the Syllinum section [15], where some species are described as PTOX producers with most of the studies related to L. flavum, L. mucronatum and L. album. Lignans are found in the flowering aerial part [16], in seeds [17] and in roots [18].

It has been extensively reported that plant cell cultures can overcome the bottleneck due to the long time required for field cultivation of the plant material, and that metabolite production of these cultures can be induced through elicitor treatments [19]. Elicitors are often used to stimulate the production of plant secondary metabolites in diverse species [15]. In particular, elicitors such as methyl jasmonate (MeJA) or coronatine (COR) have been reported to enhance lignans production in several Linum species [20].

However, despite the fact that some biopharmaceutical molecules are produced via cell line cultures [15,21,22], it is generally recognized that some limitations occur, such as low and variable yields of metabolites and genetic instability. The low yield of secondary metabolites in cell cultures has been explained by the lack of cell differentiation. Then, an alternative strategy to cell culture is the organized tissue culture of roots or shoots [23]. A wide range of natural products has been produced using adventitious and hairy-root cultures, including lignans, exploiting their high genetic stability, biosynthetic capabilities, biomass production and the possibility to be used for several successive generations [24]. These tissues can be cultivated in large-scale bioreactors for commercial production of bioactive compounds and can be elicited to obtain a higher yield. Until recently, genetically transformed hairy roots had received more attention for phytochemicals production than adventitious roots. However, the adventitious roots cultures (ARc) are emerging since they are considered the more natural material (untransformed) thus leading to their high commercial value compared to hairy roots.

In this study, L. flavum, L. mucronatum and L. dolomiticum ARc were obtained and the effect of two elicitors, MeJA and COR, was investigated on ATLs production and compared among these species for the first time. The antioxidant capacity, total phenols and flavonoids content of root extracts were also assessed. The ATLs were purified by preparative TLC and HPLC and structurally determined by NMR.

\section{Results}

\subsection{ARc Production and Effect of Elicitation Treatments}

ARc were obtained from three Linum species: flavum, mucronatum and dolomiticum. All the ARc obtained from the three species showed both good stability and biomass production, referred to as FW, over a 25-day growth period (Figure 1).

This growing time was adopted since the three Linum ARc needed almost 8-10 days of adaptation to the liquid medium before entering exponential growth. Then, on day 21 MeJA and COR treatments were applied to the cultures for four days. The use of MeJA and COR on the ARc of the species considered in this work is reported for the first time, even though their use was already reported for cell suspensions and ARc of other Linum species. As shown in Figures 1 and 2, the elicitor treatments caused an inhibition of growth as already reported for other species [25]. A two-way analysis of variance (ANOVA, Table S1) highlighted a reduction on the final growth of L. flavum and L. mucronatum ARc after the addition of MeJA or COR (Figure 2). On the contrary, in L. dolomiticum ARc, MeJA and COR did not significantly inhibit growth (Figure 2). 


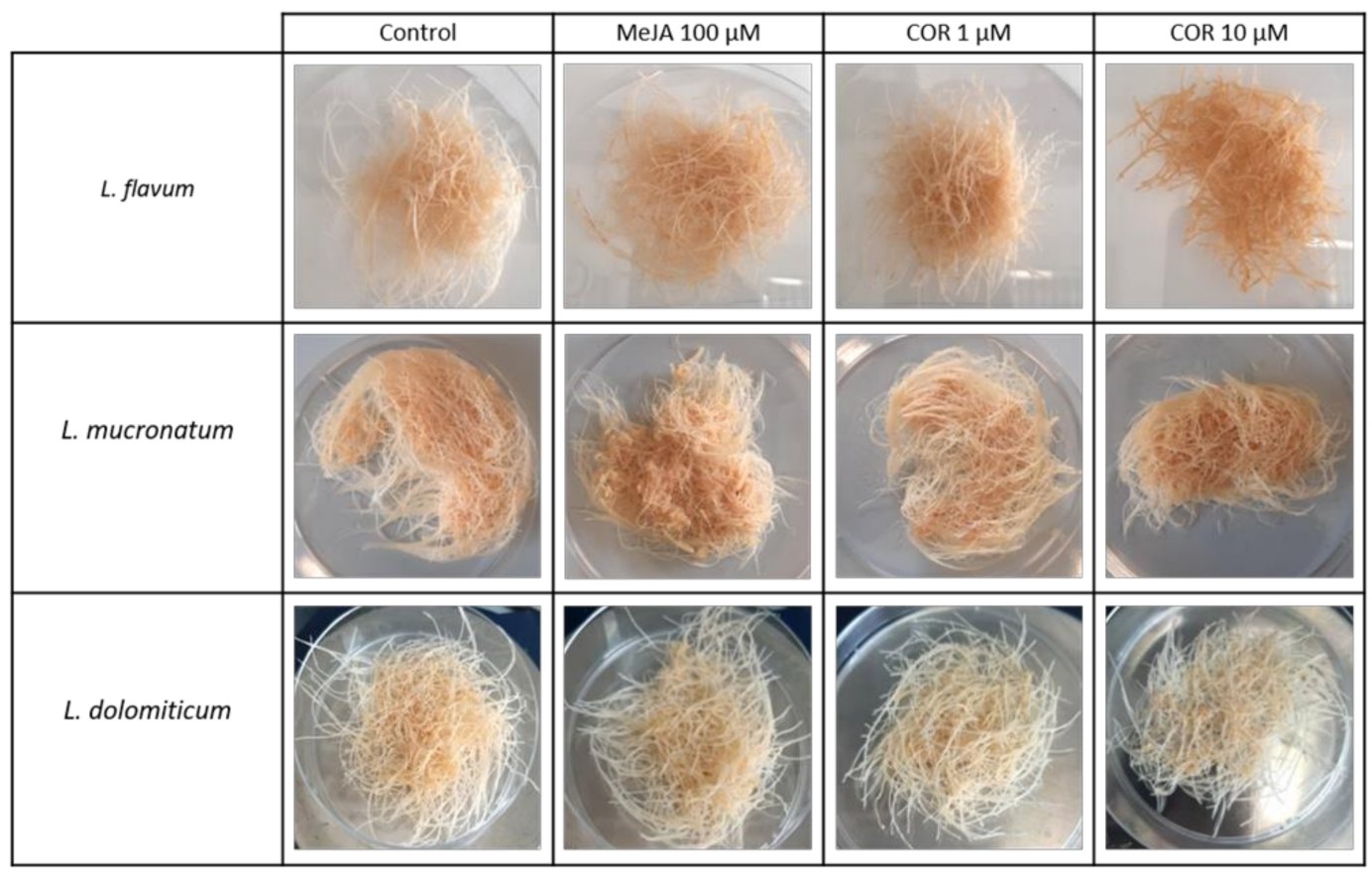

Figure 1. ARc from L. flavum, L. dolomiticum and L. mucronatum grown for 25 days on MS-II medium with or without elicitors: $100 \mu \mathrm{M}$ MeJA, $1 \mu \mathrm{M}$ COR, $10 \mu \mathrm{M}$ COR.

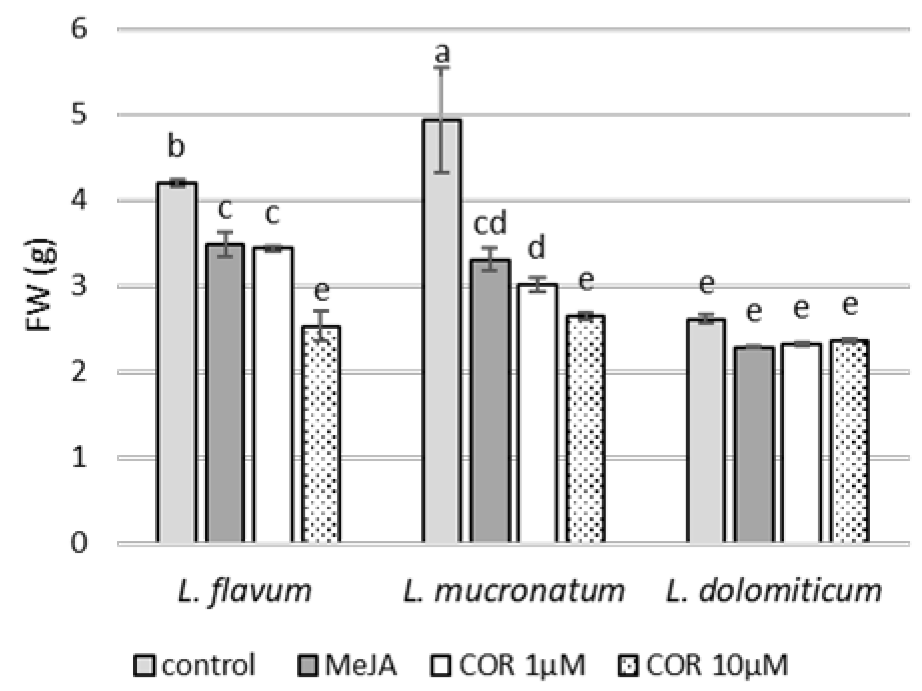

Figure 2. Effect of elicitors on the growth of ARc of L. flavum, L. mucronatum and L. dolomiticum over a cultivation period of 25 days in MS-II liquid medium expressed as fresh weight (FW) in grams; control (light gray), MeJA (100 $\mu \mathrm{M}$, dark gray), COR $1 \mu \mathrm{M}$ (white), COR $10 \mu \mathrm{M}$ (dotted). Each value is the mean of three biological replicates $\pm \mathrm{SD}$. The samples with different letters are significantly different at $p \leq 0.05$ according to Duncan test. The growth index of each ARc culture is reported from left to right; L. flavum: 4.2, 3.4, 3.3, 2.2; L. mucronatum: 5.2, 3.1, 2.8, 2.3; L. dolomiticum: 2.3, 1.9, 1.9, 2.0.

\subsection{Total Phenols, Total Flavonoids Content and DPPH Radical Scavenging Activity}

Before estimating the ATLs content, the total phenols, the total flavonoids and the antioxidant capacity of the ARc extracts were investigated in function of the two elicitors MeJA and COR.

The results were analyzed using two-way analysis of variance (ANOVA, Table S1), a pairwise comparison test (Tukey's HSD, Figures S6-S8) and a multiple-comparison test (Duncan test, Figure 3) in order to compare three different species of Linum and four different treatments on the accumulation of phenols, flavonoids and antioxidant 
capacity. Both factors (species and elicitor treatments) and their interaction were found to be significant (Table S1). The total phenol content, expressed as gallic acid equivalent (GAE) (Figure 3A), indicated a marked influence of the elicitor in all the three ARc species. In L. flavum treated with COR at both concentrations, the production of phenols was nearly three times compared to the control or to MeJA. In L. dolomiticum, MeJA nearly doubled the amount of total phenol compared to the control, and COR had an even stronger effect. The control samples of L. mucronatum showed a higher level of phenols than the other species and the increase due to the elicitation was less prominent. It is noteworthy that the maximum amount of total phenol reached after COR elicitation was similar regardless to the plant species. The flavonoid content was measured as quercetin equivalent $(\mathrm{QE})$ (Figure 3B). As for total phenols, the flavonoid level was enhanced by COR more than MeJA apart from L. dolomiticum where the increase due to the elicitors was flattened (Figure 3B).

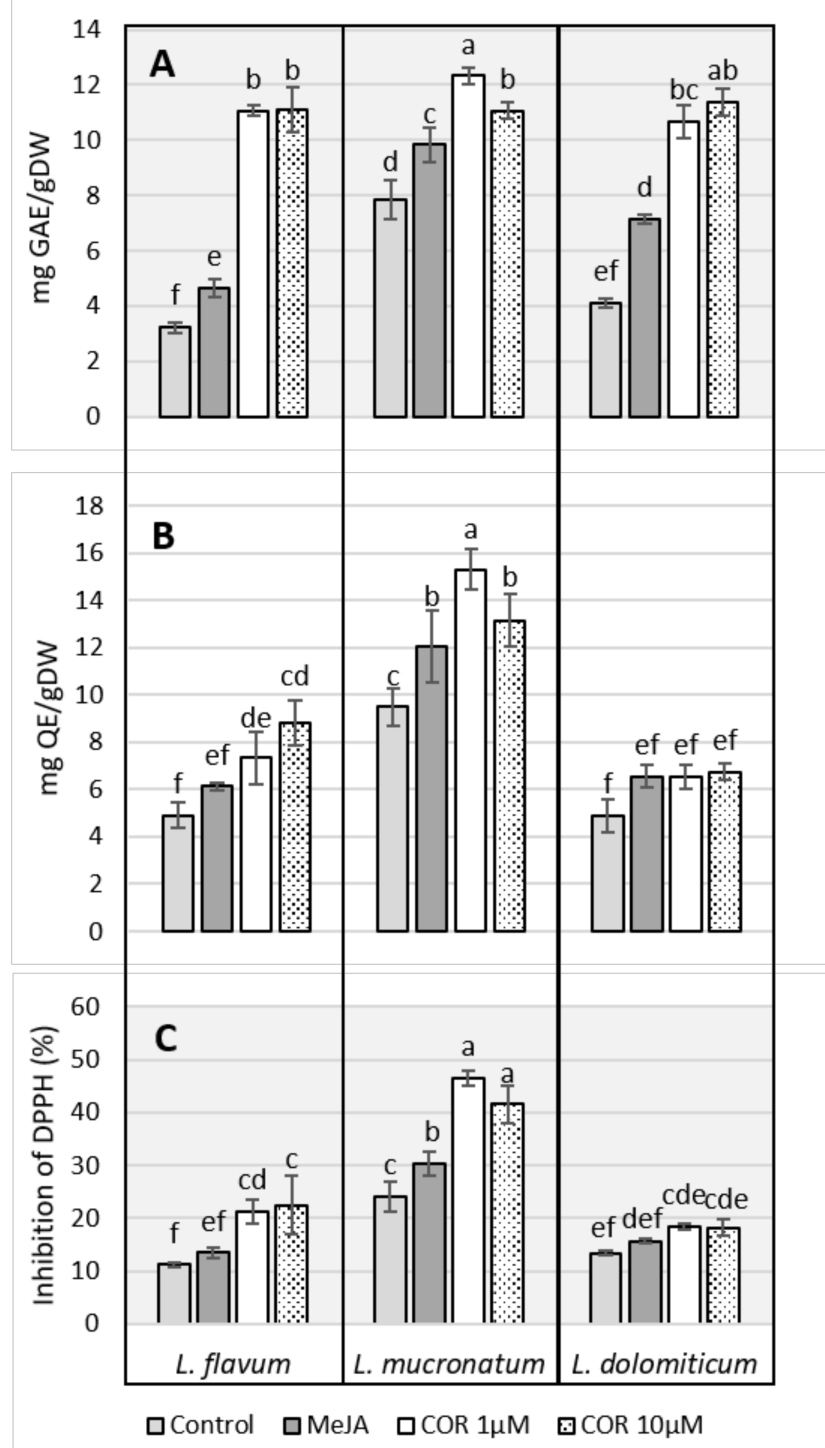

Figure 3. Effect of elicitors on L. flavum, L. mucronatum and L. dolomiticum ARc; control (light gray), MeJA (100 $\mu \mathrm{M}$, dark gray), COR $1 \mu \mathrm{M}$ (white), COR $10 \mu \mathrm{M}$ (dotted). (A) Phenol content expressed as gallic acid equivalent, $\mathrm{mg}$ GAE/g DW. (B) Flavonoid content expressed as quercetin equivalent, $\mathrm{mg}$ QE/g DW. (C) Antioxidant capacity expressed as percent of inhibition of DPPH. Each value is the mean of three biological replicates \pm SD. The samples with different letters are significantly different at $p \leq 0.05$ according to Duncan test. 
The antioxidant capacity evaluated as the scavenging of DPPH free radicals is reported in Figure 3C. Elicitors were found to increase the antioxidant capacity of the ARc, with COR showing a stronger effect than MeJA, especially in L. flavum and L. mucronatum. L. dolomiticum showed minor differences among the treatments. In general, the elicitation due to COR was stronger than MeJA, as well as at lower concentration $(1 \mu \mathrm{M})$. It seems that the best match between elicitor concentration and biomass growth inhibition in our ARc is reached with $1 \mu \mathrm{M}$ COR. The reaction of DPPH with the ARc extracts was also performed on a TLC plate after chromatographic separation (Figure S1). The result obtained confirms that L. mucronatum ARc has the strongest DPPH radical scavenging activity as highlighted in Figure $3 C$ and suggests that this activity is mainly due to the presence of a specific compound with $R_{\mathrm{f}} 0.53$ that was not detectable in ARc extracts from L. flavum and $L$. dolomiticum.

\subsection{NMR Identification of ATLS}

The accumulation of ATLs in the ARc from L. flavum, L. mucronatum and L. dolomiticum was studied. The typical HPLC chromatogram profile of the adventitious root extracts is reported in Figure 4 for the aryltetralin lignan portion centered on PTOX retention time (see Figure $\mathrm{S} 2$ for the whole chromatogram). The amount of PTOX, $\mathrm{R}_{\mathrm{t}} 22.2 \mathrm{~min}$, was very small compared to other compounds, and below the limit of detection (LOD) in L. mucronatum. In the same portion of the HPLC profile, two other signals were recorded at $R_{t}$ of 18.8 and 23.9 min. These molecules were purified by means of TLC and HPLC and identified by NMR (Figures S3 and S4).
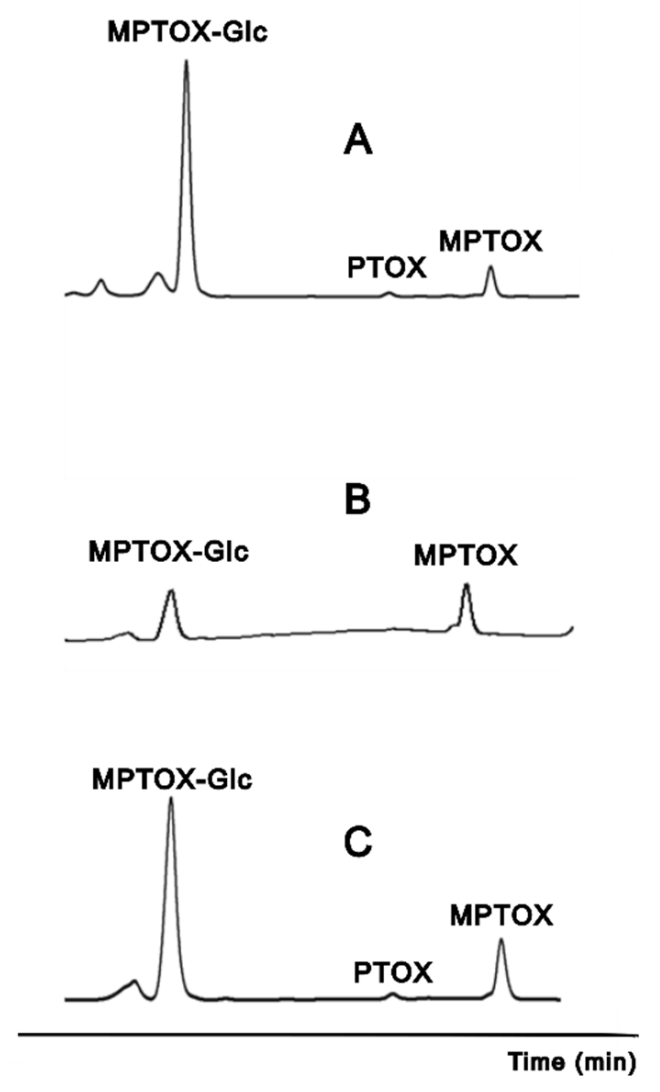

Figure 4. HPLC chromatograms of the ATLs portion, 18 to $24 \mathrm{~min}$ at $254 \mathrm{~nm}$, COR-treated extract from (A): L. flavum, (B): L. mucronatum (C): L. dolomiticum. MPTOX-Glc $\left(\mathrm{R}_{\mathrm{t}} 18.8 \mathrm{~min}\right)$, PTOX $\left(\mathrm{R}_{\mathrm{t}} 22.2 \mathrm{~min}\right)$ and MPTOX ( $\left.R_{t} 23.9 \mathrm{~min}\right)$ were identified. See also Figure $\mathrm{S} 2$ for the whole chromatogram. 
Two molecules were purified by preparative TLC of the L. flavum sample. The ${ }^{1} \mathrm{H}-$ NMR spectra revealed the signals of 6-methoxypodophillotoxin (Figure S3) and the signals corresponding to 6-methoxypodophyllotoxin-7-O- $\beta$-glucoside (Figure S4), in full agreement with previous NMR assignments of these molecules [26].

\subsection{Quantitative Analyses of ATLs}

The compounds identified by ${ }^{1} \mathrm{H}-\mathrm{NMR}$ were quantified in all the ARc samples, the control and those treated with the elicitors. The results obtained after 25 days of culture are reported in Figure 5. A statistical analysis was applied using two-way ANOVA (Table S2), a pairwise comparison test (Tukey's HSD, Figures S9-S11) and a multiple-comparison test (Duncan test, Figure 5) to compare the effect of the species and the elicitor treatments. Both factors, species and treatments, and their interaction were found to be significant for the accumulation of PTOX and MPTOX (Table S2). Conversely, the elicitor treatment was not significant for the accumulation of MPTOX-Glc. Among the three Linum species, PTOX was the least abundant lignan reaching $1.67 \mathrm{mg} / \mathrm{g}$ DW in L. flavum ARc with an increase after $1 \mu \mathrm{M}$ COR elicitation up to $2.46 \mathrm{mg} / \mathrm{g}$ DW and becoming negligible in the presence of $10 \mu \mathrm{M}$ COR (Figure 5). In the case of L. mucronatum ARc, PTOX was not detected even under elicitation. The production of PTOX by L. dolomiticum ARc was $2.55 \mathrm{mg} / \mathrm{g}$ DW under $1 \mu \mathrm{M}$ COR elicitation, being almost undetectable in control samples (Figure 5). Conversely, the most represented compounds present in the ARc of the three Linum species were MPTOX and MPTOX-Glc (Figure 5).

The highest productive species in terms of MPTOX was L. dolomiticum with $10.7 \mathrm{mg} / \mathrm{g}$ DW with an increase up to $17.2 \mathrm{mg} / \mathrm{g}$ DW after MeJA elicitation. The production of MPTOX-Glc, (Figure 5) showed large differences among the ARc of the three species. In detail, L. flavum reached $44.0 \mathrm{mg} / \mathrm{g}$ DW with a slight but not significant increase after elicitation, while L. mucronatum showed the lowest production with $14.3 \mathrm{mg} / \mathrm{g} \mathrm{DW}$ in the control condition with an increase to $23.4 \mathrm{mg} / \mathrm{g}$ DW after MejA elicitation. The most productive species was L. dolomiticum with an MPTOX-Glc production of $70.8 \mathrm{mg} / \mathrm{g}$ DW rising to $92.6 \mathrm{mg} / \mathrm{g}$ DW after $10 \mu \mathrm{M}$ COR elicitation. Our results indicate ARc of $L$. dolomiticum as the best producer among the three species investigated.

The culture media were also analyzed by HPLC to verify whether the lignans produced were excreted in the medium; however, the presence of PTOX, MPTOX or MPTOX-Glc were not detected.

To clarify the relationships among all the compounds analyzed in response to the elicitor treatments, the Pearson correlation was performed. This analysis (Figure S12) highlighted, for each treatment, that there is a high significant negative correlation between the groups of the aryltetralins and the phenols, flavonoids and antioxidant activity. These correlations were particularly strong for the COR $1 \mu \mathrm{M}$, followed by MeJA and COR $10 \mu \mathrm{M}$. 


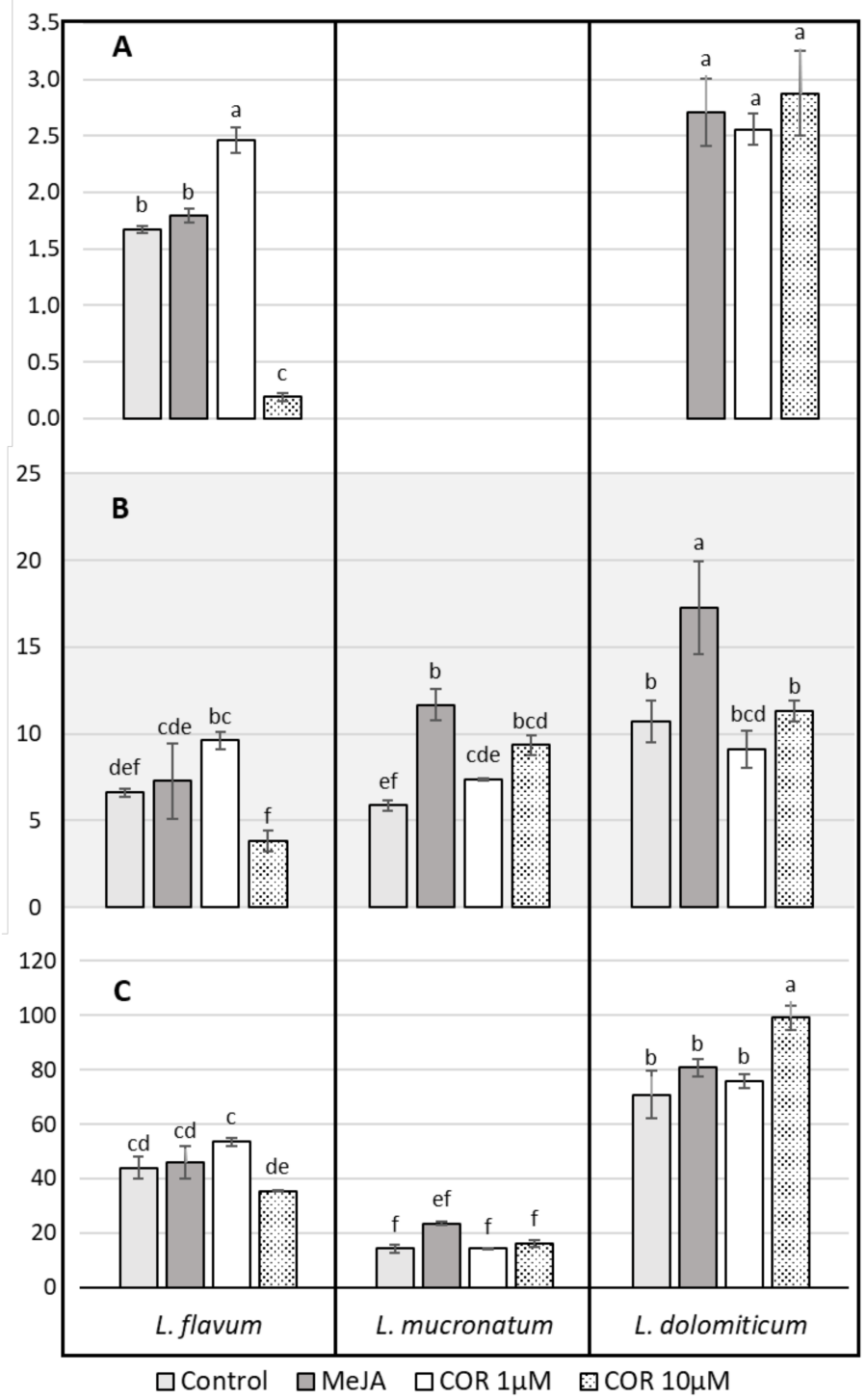

Figure 5. ATL content (mg/g DW): (A): PTOX; (B): MPTOX; (C): MPTOX-Glc. Control (light gray), MeJA (100 $\mu \mathrm{M}$, dark gray), COR $1 \mu \mathrm{M}$ (white), COR $10 \mu \mathrm{M}$ (dotted). Each value is the mean of three biological replicates \pm SD. The samples with different letters are significantly different at $p \leq 0.05$ according to Duncan test.

\section{Discussion}

The presence of ATLs (podophyllotoxin-like molecules) have been described in the Syllinum section of the genus Linum, mainly in the species L. flavum, L. mucronatum, L. album and L. nodiflorum [15]. Cell suspension or callus cultures as well as hairy roots of such species have been produced and shown to accumulate different ATLs, with the hairy roots being the most productive tissue [27-29]. Among the various tissue cultures, ARc represent one of the best choices for secondary metabolite production especially because they do not need genetic modification, making them safer [30]. In this context, ARc was obtained from three Linum species: flavum, mucronatum and dolomiticum. ARc was established for L. dolomiticum and L. mucronatum for the first time, whereas root cultures of L. flavum were already realized [29]. In particular, L. dolomiticum was chosen for its endemic origin (linked to dolomite rock grassland) since it is well known that variability in secondary metabolite production exists among species grown in particular habitats [31]. The ARc obtained from the three species revealed good stability and good biomass production over a period of 25 days of growth. Elicitation is a well-described method to enhance secondary 
metabolites production by tissue cultures. In particular, MeJA and COR represent two hormonal elicitors with a demonstrated role in increasing secondary metabolites synthesis through signal transduction by activating key differentially expressed genes (DEGs) in biosynthetic pathways from the secondary metabolite of interest [25]. The use of MeJA and COR on the ARc of the species considered in this work is reported for the first time, whereas several studies describe their use on cell suspensions, adventitious or hairy roots of other Linum species [32-34]. As reported for other species, the elicitor treatment affected ARc growth differently in the three species considered: A marked inhibitory effect was observed for L. flavum and L. mucronatum ARc and no effect was evident for L dolomiticum ARc. Regarding the effect of elicitors on phenols and flavonoids accumulation and on the antioxidant capacity, COR seems to be more effective than MeJA. However, in the case of L. dolomiticum Arc, the flavonoids and antioxidant capacity was almost unaffected by the treatments. The fact that there is not a striking difference between the two different concentrations of COR suggest the presence of a threshold concentration common to all the species analyzed. Furthermore, looking at the absolute concentrations, there seems to be a trade-off between growth and productivity. Indeed, it has been reported that lower elicitor concentrations result in better biomass growth and productivity of the culture (i.e., paclitaxel production) [35]. The production of ATLs lignans has been described for several Linum species from the section Syllinum both from cell suspension and hairy roots [36]. In particular, for hairy roots, a production of $0.8 \mathrm{mg} / \mathrm{g}$ DW PTOX has been described, while for L. flavum hairy roots, that was about twice that of the corresponding cell suspension with a production of $0.8 \mathrm{mg} / \mathrm{g}$ DW PTOX [36]. As far as the L. flavum whole plant is concerned, variations in ATLs content are described among the different organs, PTOX and 6-MPTOX are present in all plant organs, but a higher concentration of PTOX $(0.27-0.33 \%)$ than 6-MPTOX $(0.04-0.12 \%)$ has been found in extracts of upper plant parts, petals, leaves and productive organs [17]. However, root tissue cultures usually show higher concentrations than whole plant organs. Actually, our adventitious roots production was greater than $L$. flavum hairy roots, being twice as high in control conditions and three times higher after $1 \mathrm{mM}$ COR elicitation. These results suggest that adventitious roots could represent a very promising tissue for PTOX production. In contrast, in L. mucronatum ARc, PTOX was not detected even under elicitation.

This result is opposed to that reported by Samadi for L. mucronatum ssp. mucronatum hairy roots [37] reporting a production of $5.78 \mathrm{mg} / \mathrm{g}$ DW PTOX. This discrepancy could be due to the origin of L. mucronatum seeds used [37], which were collected from the mountain region of Iran, at an altitude of $1800 \mathrm{~m}$, with respect to our seeds that were from the Turkey region. Different climatic and pedologic environment could determine differences in biochemical traits [31].

The proposed biosynthetic pathways leading to podophyllotoxin (PTOX) and 6methoxypodophyllotxin (MPTOX) and their glucosides starts from a common precursor, (-)-deoxypodophyllotoxin, which can be directed to the synthesis of PTOX by DOP7H (deoxypodophyllotoxin 7-hydroxylase) [32] or to MPTOX by DOP6H (deoxypodophyllotoxin 6-hydroxylase) then to the corresponding glycosylate MPTOX-Glc [38]. Our data suggest that the second biosynthetic route is preferred in the ARc obtained from the three species, and that in all the experiments, the amount of $\beta$-peltatin, the precursor of MPTOX, was negligible. Despite this fact, our data demonstrate that L. dolomiticum was the highest productive species in terms of MPTOX with $10.7 \mathrm{mg} / \mathrm{g}$ DW with an increase up to $17.2 \mathrm{mg} / \mathrm{g}$ DW after MeJA elicitation, which is approximately the same amount of MPTOX produced in L. album ARc elicited with $1 \mu \mathrm{M}$ COR [32]. A recent study has demonstrated the cytotoxic activity of MPTOX toward four selected human carcinomas and against a normal fibroblast cell line and was described its mechanism of action [39], which is comparable to PTOX. Due to its antiproliferative activity, this molecule could be of interest to produce new anticancer drugs and to bypass the resistance mechanisms against podophyllotoxin-derived drugs [40]. The most striking result was the production of MPTOX-Glc by L. dolomiticum ARc, $70.8 \mathrm{mg} / \mathrm{g}$ DW rising to $92.6 \mathrm{mg} / \mathrm{g}$ DW after $10 \mu \mathrm{M}$ COR elicitation. This value is 
one of the highest reported for this molecule even when compared to hairy roots of other species $[36,37,41]$. In any case, the hairy roots are not always the most productive tissue as regards these molecules, as reported for PTOX and MPTOX in adventitious and hairy roots of L. album [32]. Our results indicate the ARc of L. dolomiticum as the best producer among the three species investigated.

The culture media were also analyzed by HPLC to verify whether the lignans produced were excreted in the medium, as reported for some Linum species in a very low amount $[25,36]$; however, the presence of PTOX, MPTOX or MPTOX-Glc were not detected. The digestion of MPTOX-Glc with $\beta$-glucosidase showed that this molecule can be easily converted to MPTOX. In a scale-up perspective, the production of MPTOX could be obtained through L. dolomiticum ARc, which produces good quantities of MPTOX and MPTO-Glc, and then the extract can be treated with $\beta$-glucosidase to obtain MPTOX if needed. The negative correlation among phenols, flavonoids and ATLs in response to the elicitor treatments suggest that the elicitation activates different pathways including those of lignans or others producing secondary metabolites belonging to the classes of phenols and flavonoids. For this reason, the ARc of L. mucronatum, accumulating more phenols and flavonoids compounds, is less suitable to produce ATLs, whereas L. dolomiticum and L. flavum ARc seem to be more performing. Regarding the use of elicitors to increase the ATLs production in Linum, we can conclude that both MeJA and COR were appropriate to activate the lignans pathway, as previously reported for other Linum species [32-34]. The same elicitors were also able to enhance the arylnaphtalenic production in L. austriacum [42]. Our studies showed that MeJA is more effective on L. mucronatum ARc and $1 \mu \mathrm{M} \mathrm{COR}$ on L. flavum ARc. In L. dolomiticum ARc, MeJA enhanced the MPTOX production whereas COR showed a better effect on MPTOX-Glc. These data confirm that signal molecules are effective in enhancing secondary metabolisms, but the effect of each elicitor, even if belonging to the same class of compound, could be different on the same species. The results obtained indicate that ARc could be a very promising tissue for secondary metabolites production especially when using the proper elicitor. This technology could have commercial applications through a scale-up process in bioreactors as reported for some species such as Hypericum perforatum and Polygonum multiflorum [43]. The main advantage for the use of ARc with respect to hairy roots is the absence of opine-like substrates (dangerous to mammalian cells) that are usually produced as byproducts of the hairy root system [44]. In general, the results reported point out that ARc represents a very good system for industrial production of bioactive compounds for their better biosynthetic ability and a great stability. Moreover, ARc could be preferred to hairy roots since they are simpler to obtain and safer.

\section{Materials and Methods}

\subsection{Chemicals}

Methyl jasmonate (MeJA), coronatine (COR), the Folin-Ciocalteu reagent, 2,2-Diphenyl1-picrylhydrazyl (DPPH), triphenyl tetrazolium chloride (TTC), Murashige and Skoog Basal Medium (MS), sucrose, gallic acid, quercetin, podophyllotoxin, $\beta$-glucosidase, indole-3acetic acid (IAA), indole-3-butyric acid (IBA), $\alpha$-naphthalene acetic acid (NAA) and salts were purchased from Merck (Darmstadt, Germany); the solvents were from Honeywell (Milan, Italy); the pre-coated TLC-plates SIL G-100/UV254 were from Macherey-Nagel (Dueren, Germany); water (purified water) was obtained from MilliQ (Millipore, Darmstadt, Germany).

\subsection{Plant Material}

Seeds of L. flavum and L. dolomiticum were purchased by Jelitto (Jelitto Staudensamen, Germany) and L. mucronatum was obtained from USDA (U.S. Department of Agriculture, Beltsville, MD, USA). The seeds were surface sterilized in $70 \%$ ethanol for $1 \mathrm{~min}$, then in a solution of sodium hypochlorite $1 \%(v / v)$ for $5 \mathrm{~min}$, washed 5 times with sterilized water and then germinated in MS basal medium [45] at $22{ }^{\circ} \mathrm{C}$ in dark conditions. After one week, the seedlings were placed at $25^{\circ} \mathrm{C}$, for one month, under $16 \mathrm{~h}$ of light and $8 \mathrm{~h}$ of darkness. 


\subsection{Establishment of ARc and Elicitor Treatments}

\subsubsection{ARc Induction}

ARc was generated from leaves collected from one-month-old plantlets of L. flavum, L. dolomiticum and L. mucronatum. The sterile leaf explants were laid horizontally on Petri dishes with solid ( $0.8 \%$ agar) MS supplemented with vitamins, $2 \mathrm{mg} / \mathrm{L} \alpha$-naphthalene acetic acid (NAA), $0.4 \mathrm{mg} / \mathrm{L}$ kinetin and $30 \mathrm{mg} / \mathrm{L}$ of sucrose. The $\mathrm{pH}$ was adjusted to 5.8 using a $\mathrm{KOH}$ solution. After 4 weeks, the length of the root segments was $0.8-1.3 \mathrm{~cm}$. In order to increase the biomass production, roots were individually transferred to halfstrength MS medium supplemented with $20 \mathrm{mg} / \mathrm{L}$ of sucrose $0.5 \mathrm{mg} / \mathrm{L}$ indole-3-butyric acid (IBA) and $0.1 \mathrm{mg} / \mathrm{L}$ indole-3-acetic acid (IAA) (shortened from now on as MS-II) and the roots were sub-cultured every month. All the ARc lines were maintained on solid agar medium as a starter material to be used for new liquid cultures.

\subsubsection{Elicitor Treatments}

For the elicitation treatment, $0.8 \mathrm{~g}$ of ARc of the three Linum species were transferred into a $250 \mathrm{~mL}$ Erlenmeyer flask containing $20 \mathrm{~mL}$ of MS-II liquid medium and were grown for 21 days at $23{ }^{\circ} \mathrm{C}$ on an orbital shaker (110 rpm) in dark condition and the medium was renewed each week. The stock solution of MeJA, dissolved in ethanol, and COR dissolved in water were prepared and added to the final concentration of MeJA $100 \mu \mathrm{M}, \mathrm{COR} 1 \mu \mathrm{M}$ and $10 \mu \mathrm{M}$, then left four days. Ethanol was added to the control samples.

\subsubsection{ARc Growth and Viability}

Root growth was measured as fresh weight (FW). Roots were harvested and washed three times with sterilized water, dried on filter paper to remove all external moisture and weighed. For the determination of root viability, a solution of $10 \mathrm{mM} \mathrm{KH}_{2} \mathrm{PO}_{4}, 3 \%$ $(w / v)$ sucrose and $0.25 \%(w / v)$ triphenyl tetrazolium chloride (TTC) was used as a visual indicator of root viability [46]. The growth of roots was monitored up to 25 days.

\subsection{Extraction}

Extraction was performed from powdered lyophilized tissues. The samples were dispersed in a hydroalcoholic solution (methanol $80 \% v / v$ ) placed in a rotary shaker at $20^{\circ} \mathrm{C}$ overnight, and finally centrifuged for $5 \mathrm{~min}$ at $13,000 \times g$. The extraction was repeated twice. The clear supernatants were collected and used for total phenolics and flavonoids determination, DPPH radical scavenging assay and chromatographic analysis. The culture medium was extracted with $4 \times 5 \mathrm{~mL} \mathrm{CHCl}_{3}$, and then the organic layers were combined, filtered and dried.

\subsection{Total Phenols, Total Flavonoids Content and DPPH Radical Scavenging Activity 4.5.1. Total Phenols Content}

The amount of total phenol was evaluated by the Folin-Ciocalteu assay reagent according to Ainsworth et al. [47] using gallic acid as a standard. Briefly, $50 \mu \mathrm{L}$ of the $80 \%(v / v)$ methanol extract solution was mixed with $750 \mu \mathrm{L}$ of water and $50 \mu \mathrm{L}$ of 10 -fold diluted Folin-Ciocalteu reagent and allowed to stand for $10 \mathrm{~min}$ at room temperature; then $150 \mu \mathrm{L}$ of the $20 \%(w / v)$ sodium carbonate solution was added to each sample and placed in the dark at room temperature for two hours. The absorbance was spectrophotometrically measured at $765 \mathrm{~nm}$. Total phenols were expressed as milligrams of gallic acid equivalent per gram of DW (mg GAE/g DW). The calibration curve range was $0-6 \mu \mathrm{g} / \mathrm{mL}$.

\subsubsection{Total Flavonoids Content}

The total flavonoids content was measured following the method of Wolfe et al. [48]. A total of $50 \mu \mathrm{L}$ of the sample diluted with $1.45 \mathrm{~mL}$ of water was mixed with $75 \mu \mathrm{L}$ of $5 \%$ sodium nitrite and incubated for $5 \mathrm{~min}$ followed by $150 \mu \mathrm{L}$ of $10 \%$ aluminum chloride for $6 \mathrm{~min}$. Finally, $500 \mu \mathrm{L}$ of $1 \mathrm{M} \mathrm{NaOH}$ was added, and the mixture was adjusted to $2.5 \mathrm{~mL}$ with water. The absorbance versus the prepared blank was spectrophotometrically 
measured at $425 \mathrm{~nm}$ after $10 \mathrm{~min}$. The total flavonoids contents of the different treatments were expressed as milligrams of quercetin equivalents per gram of dry matter (mg QE/g DW). The calibration curve range was $0-3.2 \mu \mathrm{g} / \mathrm{mL}$.

\subsubsection{DPPH Radical Scavenging Activity}

The free radical scavenging activities of plant extracts were determined using DPPH free radical assay [49] using $50 \mu \mathrm{L}$ of each sample extract and $2950 \mu \mathrm{L}$ of $80 \%$ aqueousmethanolic $0.102 \mathrm{mM}$ DPPH. After $15 \mathrm{~min}$ the absorbance reduction was spectrophotometrically measured at $515 \mathrm{~nm}$. The ability to scavenge DPPH was calculated as follows:

$$
(\%) \text { DPPH radical scavenging activity }=[(\text { Act }- \text { Asa }) / \text { Act }] \times 100
$$

where Act is the absorbance of DPPH radical plus methanol and Asa is that of DPPH radical plus the sample extract. Radical scavenging activity is shown as the percentage of DPPH inhibition for $\mathrm{mg}$ of DW.

\subsubsection{HPTLC-DPPH Test}

TLC-DPPH test was used to screen the presence of free radical scavenger spots. Each extract (control, MeJA and $1 \mu \mathrm{M}$ COR) was applied on HPTLC Silica Gel 60 F254 aluminum sheets with a distance of $4 \mathrm{~mm}$ between them using Linomate 5 controlled by winCATS software version 3.0. The plate was developed, to a distance of $90 \mathrm{~mm}$, in a vertical chamber pre-saturated for $20 \mathrm{~min}$ with a mobile phase for phenolic acid composed of chloroform/ethyl acetate/acetone/formic acid (4:3:2:1), then dried and observed at $366 \mathrm{~nm}$ [50]. The plate was sprayed with DPPH 0.05\% in methanol and kept in dark conditions for $30 \mathrm{~min}$. The radical scavenging activity was detected by the discoloration of DPPH.

\subsection{HPLC Analysis}

HPLC analysis was carried out using Jasco instruments equipped with a photodiode array detector. Separation was performed using a Synergi polar RP $80 \AA$ ( $(250 \mathrm{~mm} \times 4.60 \mathrm{~mm}$, $4 \mu \mathrm{m}$, Phenomenex) and a gradient system consisting of water (A) and acetonitrile (B) as follows: $0-20 \%$ B for the first $15 \mathrm{~min}, 20-70 \%$ B from 15 to $25 \mathrm{~min}, 70 \%$ B for $3 \mathrm{~min}$ and $70-0 \% \mathrm{~B}$ up to $30 \mathrm{~min}$. The flow rate was $1.0 \mathrm{~mL} / \mathrm{min}$, the injection volume was $50 \mu \mathrm{L}$ and the wavelength used for the integration of the signals was $250 \mathrm{~nm}$. Quantification was performed using calibration curves of each standard as reported in Table 1.

Table 1. HPLC calibration curve data.

\begin{tabular}{|c|c|c|c|c|c|c|}
\hline Analytes & $\mathbf{R}_{t}(\min )$ & $\begin{array}{l}\text { Concentration } \\
\text { Range (mg/L) }\end{array}$ & Regression Equation & $\begin{array}{c}\text { Correlation } \\
\text { Coefficient }\left(R^{2}\right)\end{array}$ & $\begin{array}{c}\text { LOD } \\
(\mathrm{mg} / \mathrm{L})\end{array}$ & LOQ (mg/L) \\
\hline PTOX & 22.2 & $250-1700$ & $y=639956.6 x+625206.9$ & 0.9999 & 20.2 & 67.3 \\
\hline MPTOX & 23.9 & $107-533$ & $y=509126.1 x-508145.6$ & 0.9985 & 23.1 & 76.9 \\
\hline MPTOX_Glc & 18.8 & $125-1000$ & $y=334707.7 x-586706.3$ & 0.9994 & 32.7 & 109.0 \\
\hline
\end{tabular}

\subsection{Preparative TLC, Semi-Preparative HPLC}

The roots collected after 25 days were used for lignans extraction as previously described. The organic fraction was subjected to preliminary preparative TLC separation (mobile phase $\mathrm{CH}_{3} \mathrm{OH}-\mathrm{CHCl}_{3}$ ). The major bands were collected (MPTOX Rf $0.24(1 / 99 \mathrm{v} / \mathrm{v})$; MPTOX-Glc Rf $0.59(15 / 85 \mathrm{v} / \mathrm{v})$ and subjected to purification by means of semi-preparative HPLC. Separation was carried out with Synergi hydro RP $80 \AA$ (250 mm $\times 10 \mathrm{~mm}, 4 \mu \mathrm{m}$, Phenomenex) using water and acetonitrile as eluents. The MPTOX-Glc and MPTOX obtained reached a purity up to $95 \%$. 


\subsection{NMR Identification of MPTOX and MPTOX-Glc}

Purified compounds have been dissolved in deuterated chloroform $(99.98 \%$ of $2 \mathrm{H})$ and spectra recorded on a Bruker DMX 600 spectrometer, equipped with a $5 \mathrm{~mm}$ reverse probe with a $\mathrm{z}$ gradient coil. All spectra were recorded at $25^{\circ} \mathrm{C}$ and referenced to the solvent signal for both proton and carbon chemical shifts, occurring at $7.27 \mathrm{ppm}$ and $77.2 \mathrm{ppm}$, respectively. Monodimensional ${ }^{1} \mathrm{H}$, bidimensional ${ }^{1} \mathrm{H}-{ }^{13} \mathrm{C}$ HSQC and $\mathrm{HMBC}$ spectra were recorded with $8000 \mathrm{~Hz}$ of sweep width over $64 \mathrm{k}$ and $2 \mathrm{k}$ data points for monodimensional and bidimensional experiments, respectively.

\subsection{Digestion of MPTOX-Glc with $\beta$-Glucosidase}

An aliquot of $85 \mu \mathrm{g}$ of purified MPTOX-Glc was digested with $20 \mathrm{U}$ of $\beta$-glucosidase from almonds. The reaction was carried out in a phosphate buffer $\mathrm{pH} 5.0$ at $25^{\circ} \mathrm{C}$ for $24 \mathrm{~h}$. The digested extracts were analyzed by HPLC at 2, 4, 6 and $24 \mathrm{~h}$.

\subsection{Statistical Analysis}

The results were subjected to statistical analysis by means of $\mathrm{R}$ (see Statistical Report in the Supplementary Materials).

Supplementary Materials: The following are available online, Figure S1: TLC plate of lignans extracts after reaction with DPPH, Figure S2: HPLC chromatogram, Figures S3 and S4: NMR spectra. Statistical Report. Table S1: Two-way ANOVA of growth, phenols, flavonoids and antioxidant capacity, Figures S5-S8: Tukey HSD post hoc test for growth, Table S2: Two-way ANOVA on ATLs, Figure S9: Tukey HSD post hoc test for PTOX, Figure S10: Tukey HSD post hoc test for MPTOX, Figure S11: Tukey HSD post hoc test for MPTOX-Glc, Figure S12: Correlation graphs.

Author Contributions: Conceptualization, M.A., I.M., M.M. and G.O.; validation, M.A. and G.O.; formal analysis, M.A. and G.O.; investigation, M.A., I.M., R.A.D.K., R.C. and F.L.; writing-original draft preparation, M.A. and G.O.; writing-review and editing, M.M. and G.O.; project administration, R.C., M.M. and G.O.; funding acquisition, M.M. All authors have read and agreed to the published version of the manuscript.

Funding: This research was funded by Fondazione Cariplo, grant number 2016-0700, InFlaMe project.

Institutional Review Board Statement: Not applicable.

Informed Consent Statement: Not applicable.

Data Availability Statement: Not applicable.

Conflicts of Interest: The authors declare no conflict of interest.

Sample Availability: Not available.

\section{References}

1. Gordaliza, M.; García, P.A.; del Corral, J.M.M.; Castro, M.A.; Gómez-Zurita, M.A. Podophyllotoxin: Distribution, Sources, Applications and New Cytotoxic Derivatives. Toxicon Off. J. Int. Soc. Toxinol. 2004, 44, 441-459. [CrossRef] [PubMed]

2. Hano, C.; Corbin, C.; Drouet, S.; Quéro, A.; Rombaut, N.; Savoire, R.; Molinié, R.; Thomasset, B.; Mesnard, F.; Lainé, E. The Lignan (+)-Secoisolariciresinol Extracted from Flax Hulls Is an Effective Protectant of Linseed Oil and Its Emulsion against Oxidative Damage. Eur. J. Lipid Sci. Technol. 2017, 119, 1600219. [CrossRef]

3. Park, S.; Kim, S.; Shin, D. Arylnaphthalene Lactones: Structures and Pharmacological Potentials. Phytochem. Rev. 2021, 22. [CrossRef]

4. Cui, Q.; Du, R.; Liu, M.; Rong, L. Lignans and Their Derivatives from Plants as Antivirals. Molecules 2020, 25, 183. [CrossRef]

5. Nitiss, J.L. Targeting DNA Topoisomerase II in Cancer Chemotherapy. Nat. Rev. Cancer 2009, 9, 338-350. [CrossRef]

6. Albertson, A.K.F.; Lumb, J.-P. The Lignans. In Recent Advances in Polyphenol Research; John Wiley \& Sons Ltd.: Chichester, UK, 2019; pp. 1-70, ISBN 978-1-119-42789-6.

7. Suzuki, S.; Umezawa, T. Biosynthesis of Lignans and Norlignans. J. Wood Sci. 2007, 53, 273-284. [CrossRef]

8. Liu, Y.-Q.; Yang, L.; Tian, X. Podophyllotoxin: Current Perspectives. Curr. Bioact. Compd. 2007, 3, 37-66. [CrossRef]

9. Lalaleo, L.; Khojasteh, A.; Fattahi, M.; Bonfill, M.; Cusido, R.M.; Palazon, J. Plant Anti-Cancer Agents and Their Biotechnological Production in Plant Cell Biofactories. Curr. Med. Chem. 2016, 23, 4418-4441. [CrossRef] [PubMed] 
10. Lazzarotto, M.; Hammerer, L.; Hetmann, M.; Borg, A.; Schmermund, L.; Steiner, L.; Hartmann, P.; Belaj, F.; Kroutil, W.; Gruber, K.; et al. Chemoenzymatic Total Synthesis of Deoxy-, Epi-, and Podophyllotoxin and a Biocatalytic Kinetic Resolution of Dibenzylbutyrolactones. Angew. Chem. Int. Ed. 2019, 58, 8226-8230. [CrossRef]

11. Li, J.; Zhang, X.; Renata, H. Asymmetric Chemoenzymatic Synthesis of (-)-Podophyllotoxin and Related Aryltetralin Lignans. Angew. Chem. Int. Ed. 2019, 58, 11657-11660. [CrossRef]

12. Yu, X.; Che, Z.; Xu, H. Recent Advances in the Chemistry and Biology of Podophyllotoxins. Chem. Eur. J. 2017, 23, 4467-4526. [CrossRef]

13. Ardalani, H.; Avan, A.; Ghayour-Mobarhan, M. Podophyllotoxin: A Novel Potential Natural Anticancer Agent. Avicenna J. Phytomed. 2017, 7, 285-294.

14. Muir, A.D.; Westcott, N.D.; Westcott, N.D. Flax: The Genus Linum; CRC Press: Boca Raton, FL, USA, 2003; ISBN 978-0-429-20585-9.

15. Malik, S.; Bíba, O.; Grúz, J.; Arroo, R.R.J.; Strnad, M. Biotechnological Approaches for Producing Aryltetralin Lignans from Linum Species. Phytochem. Rev. 2014, 13, 893-913. [CrossRef]

16. Schmidt, T.J.; Hemmati, S.; Klaes, M.; Konuklugil, B.; Mohagheghzadeh, A.; Ionkova, I.; Fuss, E.; Wilhelm Alfermann, A. Lignans in Flowering Aerial Parts of Linum Species-Chemodiversity in the Light of Systematics and Phylogeny. Phytochemistry 2010, 71, 1714-1728. [CrossRef] [PubMed]

17. Schmidt, T.J.; Klaes, M.; Sendker, J. Lignans in Seeds of Linum Species. Phytochemistry 2012, 82, 89-99. [CrossRef] [PubMed]

18. Berlin, J.; Bedorf, N.; Mollenschott, C.; Wray, V.; Sasse, F.; Höfle, G. On the Podophyllotoxins of Root Cultures of Linum flavum. Planta Med. 1988, 54, 204-206. [CrossRef] [PubMed]

19. Espinosa-Leal, C.A.; Puente-Garza, C.A.; García-Lara, S. In Vitro Plant Tissue Culture: Means for Production of Biological Active Compounds. Planta 2018, 248, 1-18. [CrossRef] [PubMed]

20. Namdeo, A. Plant Cell Elicitation for Production of Secondary Metabolites: A Review. Pharmacogn. Rev. 2007, 1, 69-79.

21. Phyton Biotech. Available online: https://phytonbiotech.com/ (accessed on 22 August 2021).

22. Fuss, E. Lignans in Plant Cell and Organ Cultures: An Overview. Phytochem. Rev. 2003, 2, 307-320. [CrossRef]

23. Verpoorte, R.; Memelink, J. Engineering Secondary Metabolite Production in Plants. Curr. Opin. Biotechnol. 2002, 13, 181-187. [CrossRef]

24. Murthy, H.N.; Dandin, V.S.; Paek, K.-Y. Tools for Biotechnological Production of Useful Phytochemicals from Adventitious Root Cultures. Phytochem. Rev. 2016, 15, 129-145. [CrossRef]

25. Bektas, Y.; Eulgem, T. Synthetic Plant Defense Elicitors. Front. Plant Sci. 2015, 5, 1-17. [CrossRef] [PubMed]

26. Wichers, H.J.; Versluis-De Haan, G.G.; Marsman, J.W.; Harkes, M.P. Podophyllotoxin Related Lignans in Plants and Cell Cultures of Linum flavum. Phytochemistry 1991, 30, 3601-3604. [CrossRef]

27. Mohagheghzadeh, A.; Hemmati, S.; Alfermann, A.W. Quantification of Aryltetralin Lignans in Linum album Organs and In Vitro Cultures. Iran. J. Pharm. Sci. 2006, 2, 47-56.

28. Konuklugil, B.; Schmidt, T.J.; Alfermann, A.W. Accumulation of Lignans in Suspension Cultures of Linum mucronatum ssp. Armenum (Bordz.) Davis. Z. Nat. C J. Biosci. 2001, 56, 1164-1165. [CrossRef] [PubMed]

29. Berlin, J.; Wray, V.; Mollenschott, C.; Sasse, F. Formation of Beta-Peltatin-A Methyl Ether and Coniferin by Root Cultures of Linum flavum. J. Nat. Prod. 1986, 49, 435-439. [CrossRef]

30. Gaosheng, H.; Jingming, J. Production of Useful Secondary Metabolites Through Regulation of Biosynthetic Pathway in Cell and Tissue Suspension Culture of Medicinal Plants; IntechOpen: London, UK, 2012; ISBN 978-953-51-0787-3.

31. Figueiredo, A.C.; Barroso, J.G.; Pedro, L.G.; Scheffer, J.J.C. Factors Affecting Secondary Metabolite Production in Plants: Volatile Components and Essential Oils. Flavour Fragr. J. 2008, 23, 213-226. [CrossRef]

32. Lalaleo, L.; Alcazar, R.; Palazon, J.; Moyano, E.; Cusido, R.M.; Bonfill, M. Comparing Aryltetralin Lignan Accumulation Patterns in Four Biotechnological Systems of Linum album. J. Plant. Physiol. 2018, 228, 197-207. [CrossRef]

33. Ionkova, I. Effect of Methyl Jasmonate on Production of Ariltetralin Lignans in Hairy Root Cultures of Linum tauricum. Pharmacogn. Res. 2009, 1, 102-105.

34. Sasheva, P.; Ionkova, I.; Stoilova, N. Methyl Jasmonate Induces Enhanced Podophyllotoxin Production in Cell Cultures of Thracian Flax (Linum thracicum ssp. Thracicum). Nat. Prod. Commun. 2015, 10, 1225-1228. [CrossRef] [PubMed]

35. Kashani, K.; Jalali Javaran, M.; Sabet, M.S.; Moieni, A. Identification of Rate-Limiting Enzymes Involved in Paclitaxel Biosynthesis Pathway Affected by Coronatine and Methyl- $\beta$-Cyclodextrin in Taxus baccata L. Cell Suspension Cultures. DARU J. Pharm. Sci. 2018, 26, 129-142. [CrossRef] [PubMed]

36. Renouard, S.; Corbin, C.; Drouet, S.; Medvedec, B.; Doussot, J.; Colas, C.; Maunit, B.; Bhambra, A.S.; Gontier, E.; Jullian, N.; et al. Investigation of Linum flavum (L.) Hairy Root Cultures for the Production of Anticancer Aryltetralin Lignans. Int. J. Mol. Sci. 2018, 19, 990. [CrossRef] [PubMed]

37. Samadi, A.; Jafari, M.; Nejhad, N.M.; Hossenian, F. Podophyllotoxin and 6-Methoxy Podophyllotoxin Production in Hairy Root Cultures of Liunm mucronatum ssp. Mucronatum. Pharmacogn. Mag. 2014, 10, 154-160. [CrossRef] [PubMed]

38. Federolf, K.; Alfermann, A.W.; Fuss, E. Aryltetralin-Lignan Formation in Two Different Cell Suspension Cultures of linum Album: Deoxypodophyllotoxin 6-Hydroxylase, a Key Enzyme for the Formation of 6-Methoxypodophyllotoxin. Phytochemistry 2007, 68, 1397-1406. [CrossRef] 
39. Alejandre-García, I.; Álvarez, L.; Cardoso-Taketa, A.; González-Maya, L.; Antúnez, M.; Salas-Vidal, E.; Díaz, J.F.; MarquinaBahena, S.; Villarreal, M.L. Cytotoxic Activity and Chemical Composition of the Root Extract from the Mexican Species Linum scabrellum: Mechanism of Action of the Active Compound 6-Methoxypodophyllotoxin. Evid. Based Complement. Altern. Med. ECAM 2015, 2015, 298463. [CrossRef]

40. Doussot, J.; Mathieu, V.; Colas, C.; Molinie, R.; Corbin, C.; Montguillon, J.; Banuls, L.M.Y.; Renouard, S.; Lamblin, F.; Dupre, P.; et al. Investigation of the Lignan Content in Extracts from Linum, Callitris and Juniperus Species in Relation to Their In Vitro Antiproliferative Activities. Planta Med. 2017, 83, 574-581. [CrossRef] [PubMed]

41. Mikac, S.; Markulin, L.; Drouet, S.; Corbin, C.; Tungmunnithum, D.; Kiani, R.; Kabra, A.; Abbasi, B.H.; Renouard, S.; Bhambra, A.; et al. Bioproduction of Anticancer Podophyllotoxin and Related Aryltretralin-Lignans in Hairy Root Cultures of Linum flavum L. In Plant Cell and Tissue Differentiation and Secondary Metabolites: Fundamentals and Applications; Ramawat, K.G., Ekiert, H.M., Goyal, S., Eds.; Reference Series in Phytochemistry; Springer International Publishing: Cham, Switzerland, 2021; pp. 503-540, ISBN 978-3-030-30185-9.

42. Mascheretti, I.; Alfieri, M.; Lauria, M.; Locatelli, F.; Consonni, R.; Cusano, E.; Dougué Kentsop, R.A.; Laura, M.; Ottolina, G.; Faoro, F.; et al. New Insight into Justicidin B Pathway and Production in Linum austriacum. Int. J. Mol. Sci. 2021, 22, 2507. [CrossRef]

43. Rahmat, E.; Kang, Y. Adventitious Root Culture for Secondary Metabolite Production in Medicinal Plants: A Review. J. Plant Biotechnol. 2019, 46, 143-157. [CrossRef]

44. Choi, S.M.; Son, S.H.; Yun, S.R.; Kwon, O.W.; Seon, J.H.; Paek, K.Y. Pilot-Scale Culture of Adventitious Roots of Ginseng in a Bioreactor System. Plant Cell Tissue Organ. Cult. 2000, 62, 187-193. [CrossRef]

45. Murashige, T.; Skoog, F. A Revised Medium for Rapid Growth and Bio Assays with Tobacco Tissue Cultures. Physiol. Plant. 1962, 15, 473-497. [CrossRef]

46. Steponkus, P.L.; Lanphear, F.O. Refinement of the Triphenyl Tetrazolium Chloride Method of Determining Cold Injury. Plant. Physiol. 1967, 42, 1423-1426. [CrossRef]

47. Ainsworth, E.A.; Gillespie, K.M. Estimation of Total Phenolic Content and Other Oxidation Substrates in Plant Tissues Using Folin-Ciocalteu Reagent. Nat. Protoc. 2007, 2, 875-877. [CrossRef]

48. Wolfe, K.; Wu, X.; Liu, R. Antioxidant Activity of Apple Peels. J. Agric. Food Chem. 2003, 51, 609-614. [CrossRef] [PubMed]

49. Cheng, Z.; Moore, J.; Yu, L. High-Throughput Relative DPPH Radical Scavenging Capacity Assay. J. Agric. Food Chem. 2006, 54, 7429-7436. [CrossRef]

50. Jesionek, W.; Majer-Dziedzic, B.; Choma, I.M. Separation, Identification, and Investigation of Antioxidant Ability of Plant Extract Components Using TLC, LC-MS, and TLC-DPPH. J. Liq. Chromatogr. Relat. Technol. 2015, 38, 1147-1153. [CrossRef] 